九州大学学術情報リポジトリ

Kyushu University Institutional Repository

\title{
Manufacture of Strand Board Bonded with Disposal Expanded Polystyrene as Binder
}

\section{Hermawan, Andi}

Graduate School of Bioresource and Bioenvironmental Sciences, Kyushu University

Ohuchi, Takeshi

Laboratory of Wood Working, Department of Technology, Fukuoka University of Education

Fuj imoto, Noboru

Laboratory of Wood Material Technology, Division of Biomaterial Science, Department of Forest and forest Products Sciences, Faculty of Agriculture, Kyushu University

https://doi.org/10.5109/17811

出版情報：九州大学大学院農学研究院紀要. 55 (1)，pp. 107-110，2010-02-26. Faculty of Agriculture, Kyushu University

バージョン：

権利関係 : 


\title{
Manufacture of Strand Board Bonded with Disposal Expanded Polystyrene as Binder
}

\author{
Andi HERMAWAN ${ }^{1 *}$, Takeshi OHUCHI ${ }^{2}$ \\ and Noboru FUJIMOTO
}

\author{
Laboratory of Wood Material Technology, Division of Biomaterial Science, Department of \\ Forest and forest Products Sciences, Faculty of Agriculture, Kyushu University, \\ Fukuoka City 812-8581, Japan \\ (Received October 30, 2009 and accepted November 19, 2009)
}

\begin{abstract}
The objective of this study was to evaluate the physical and mechanical properties of strand board bonded with disposal expanded polystyrene (EPS) as binder. The strand board was manufactured using strand made from Douglas-fir beams selected from construction scrap wood. The strands were oriented, and two types of three-layer (face-core-face) strand board were manufactured: one in which the board bonded with only disposal EPS (P board), and the other in which the board bonded with disposal EPS after isocyanate compound adhesive was applied to the strand ( $\mathrm{M}$ board). The physical and mechanical properties of the boards were evaluated based on the Japanese Industrial Standard for Particleboards (JIS A 5908). The main results obtained were as follows: bending strength properties and internal bond (IB) strength of P board had larger than those of type 18 PB and 24-10 PB standard. However, thickness swelling (TS) of the board was large, and the problem in water-proof property of the board remained. Bending strength properties, IB strength and TS of M board were larger than those of type 24-10 PB standard. The performance of $\mathrm{M}$ board showed equal or larger performance than those of control board.
\end{abstract}

\section{INTRODUCTION}

Recently, the products manufactured from the recycled materials are especially paid attention in the viewpoint of environmental problems. The progress of such a recycling technology of products means that material recycling makes the technology economically and environmentally attractive. Especially, disposal expended polystyrene (EPS) as a large amount of material abandoned in the advanced countries has the major concern. The amount of disposal EPS is increasing more and more due to the increasing of demand for packaging material. In Japan, disposal EPS is collected around 17-18 million tonnes annually. According to the examination of the Japan EPS Recycling Association, the recycling rate of disposal EPS in 2005 was $71 \%$, and the targeted recycling rate until 2010 is $75 \%$. In order to achieve this purpose, the development of new technology and new uses of disposal EPS is desirable.

As measures of recycling for disposal EPS, manufacturing of wood composites bonded with disposal EPS as binder could be one of the solutions. Wood composites were manufactured by arranging small pieces of wood material and then bonded together with adhesive. Most of wood composite products in the market are bonded with synthetic resin adhesive. Although, synthetic resin adhesives have many advantages, such as high bond strength and high water resistance, but most of them contain formaldehyde and a chemical agent that cause environmental problems. Therefore, it is necessary to

1 Graduate School of Bioresource and Bioenvironmental Sciences, Kyushu University, Fukuoka City 812-8581, Japan

2 Laboratory of Wood Working, Department of Technology, Fukuoka University of Education, Munakata City 811-4192, Japan

* Corresponding author (E-mail: andi@agr.kyushu-u.ac.jp) develop a new method of bonding which not using synthetic resin adhesive to avoid of those environmental problems.

In previous study on utilization of disposal EPS for wood composite manufacturing, it was found that density of the board and weight ratios of disposal EPS to wood particles were the significant factors influenced mechanical properties of particleboard (Fukuda et al., 2001). Hayashi et al., (2003) examined the possibility of manufacturing low-density particleboard bonded with disposal EPS, and it was found that modulus of rupture (MOR) and internal bond (IB) strength of the board bonded with disposal EPS under manufacturing conditions in density of $0.5 \mathrm{~g} / \mathrm{cm}^{3}$ and weight ratio of disposal EPS of $40 \%$ was equal to the type 8 particleboard (PB) of the Japanese Industrial Standard for particleboard (JIS A 5908).

The objective of this study was to evaluate the physical and mechanical properties of strand board bonded with disposal EPS as binder. That is, strand board was manufactured using strand made from Douglas-fir beams selected from construction scrap wood. The strands were oriented, and two types of three-layer (face-core-face) strand board were manufactured: one in which the board bonded with only disposal EPS, and the other in which the board bonded with disposal EPS after isocyanate compound adhesive was applied to the strand. The physical and mechanical properties of the boards were evaluated based on the JIS A 5908.

\section{MATERIALS AND METHODS}

\section{Raw material preparation}

Five kinds of Douglas-fir (Pseudotsuga menziesii) beams selected from construction scrap wood were prepared as raw materials for the strands. The density, mois- 
ture content (MC) and bending strength properties of each kind of beam are listed in Table 1. The MC of the beams was low, as shown in the Table 1 . Therefore, the strands could not be processed using a disk flaker in our laboratory. Thus, the beams were cut into blocks $250 \mathrm{~mm}$ long by cross sectional cutting, and pretreated by heating and pressurizing at $115^{\circ} \mathrm{C}$ for $900 \mathrm{~s}$ by using an autoclave. After that, the $\mathrm{MC}$ of the block was adjusted to be $55-130 \%$ by immersing the block in water. The strands were then processed by cutting them perpendicular to the grain at target dimensions of 60 or $120 \mathrm{~mm}$ long, $0.5 \mathrm{~mm}$ thick and $15 \mathrm{~mm}$ wide, respectively. The strands were oven dried to an average MC of $8.8 \%$. For the board manufacturing, all the strands were mixed based on their weight ratio obtained from each kind of raw material as shown in Table 1.

Disposal EPS tray was processed into powder form by using a grinding machine and then classified by using a sieve with a screen aperture of $500 \mu \mathrm{m}$. Disposal EPS powder passed this sieve was used to manufacture the board.

\section{Board manufacturing}

The strands were oriented, and two types of threelayer (face-core-face) strand board were manufactured: one in which the board bonded with only disposal EPS (P board), and the other in which the board bonded with disposal EPS after isocyanate compound adhesive was applied to the strand ( $\mathrm{M}$ board). The weight ratio of face-core-face was set at 1:2:1.

In our previous study (Hermawan et al., 2009), three-layer strand board was manufactured with strand

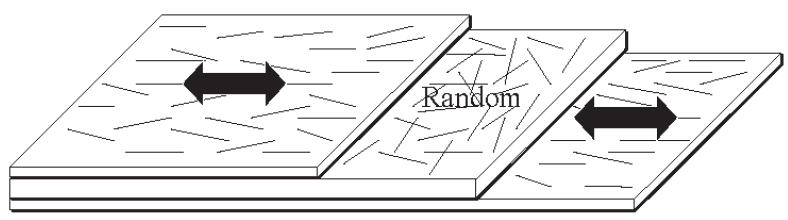

Fig. 1. Schematic diagram of strand board. of length $120 \mathrm{~mm}$ in the face layers and $60 \mathrm{~mm}$ in the core layer. When the strands of the face layers were oriented at same direction and those of the core layer were oriented at random, the mechanical properties of the board had large values. Therefore, in this study, we manufactured strand board with the same length and orientation of the strand as mentioned above. Schematic diagram of the board are shown in Fig. 1.

In manufacturing of $\mathrm{P}$ board, based on oven-dry strand weight, water of $25 \%$ was applied by using spry gun to the strand to make it easier to adhere uniformly with disposal EPS powder. And then, disposal EPS powders were added and mixed uniformly with the strand, and the board was formed. In manufacturing of M board, based on oven-dry strand weight, isocyanate compound adhesive of $3 \%$ and water of $25 \%$ was mixed and then applied to the strand by using spry gun. After that, disposal EPS powders were added and mixed uniformly with the strand, and the board was formed.

The forming size of the board was $365 \mathrm{~mm}$ long, $255 \mathrm{~mm}$ wide, and the thickness was provided by using a distance-bar $10 \mathrm{~mm}$ thick. In hot pressing conditions, the hot plate temperature was adjusted to $180^{\circ} \mathrm{C}$, and the hot press time was adjusted to $600 \mathrm{~s}$. The board was cured at room temperature for one month after hot pressing. The final dimensions were $300 \mathrm{~mm}$ length, $200 \mathrm{~mm}$ width and $10 \mathrm{~mm}$ thickness. The manufacturing conditions of this study are listed in Table 2.

\section{Board evaluation}

The physical and mechanical properties of the boards were evaluated based on the JIS A 5908. A static bending test was conducted using a Universal Testing Machine. The specimen $(220 \times 30 \times 10 \mathrm{~mm})$ for the static bending test of each type of board was prepared. Threepoint bending was applied over an effective span of $150 \mathrm{~mm}$ at a loading speed of $5 \mathrm{~mm} / \mathrm{min}$. In this test, a parallel specimen and a right-angle specimen for both $\mathrm{P}$ and $\mathrm{M}$ board were prepared. As for the parallel specimen, the long side of the specimen is parallel to the strand orientation of the face layer. As for the right-

Table 1. Properties of raw materials and weight ratio of the strand for board manufacturing

\begin{tabular}{cccccc}
\hline $\begin{array}{c}\text { Raw material } \\
\text { (Douglas-fir) }\end{array}$ & $\begin{array}{c}\text { Density } \\
\left(\mathrm{g} / \mathrm{cm}^{3}\right)\end{array}$ & MC (\%) & MOR (Mpa) & MOE (GPa) & $\begin{array}{c}\text { Weight ratios of the strand for } \\
\text { board manufacturing (\%) }\end{array}$ \\
\hline A & 0.51 & 9.3 & 105 & 11.7 & 61 \\
B & 0.53 & 9.3 & 107 & 10.0 & 8.8 \\
C & 0.39 & 9.6 & 79 & 7.2 & 25 \\
D & 0.48 & 9.9 & 78 & 6.9 & 4 \\
E & 0.38 & 9.6 & 51 & & 9 \\
\hline
\end{tabular}

Table 2. Manufacturing conditions

\begin{tabular}{cccc}
\hline \multicolumn{2}{c}{ Strand length $(\mathrm{mm})$} & Strand orientation & Binder and weight ratio \\
\hline Face layer & Core layer & & Disposal EPS 40\% \\
\hline \multirow{2}{*}{60} & Random & & Isocyanate 3\%+ Disposal EPS 25\% \\
\hline
\end{tabular}


angle specimen, the long side of the specimen is perpendicular to the strand orientation of the face layer. The specimen $(50 \times 50 \times 10 \mathrm{~mm})$ for both of internal bond (IB) strength and thickness swelling (TS) tests from each type of board was prepared, respectively.

\section{RESULTS AND DISCUSSION}

The average values of density and $\mathrm{MC}$ for $\mathrm{P}$ board were $0.74 \mathrm{~g} / \mathrm{cm}^{3}$ and $3.5 \%$, respectively. In case of $\mathrm{M}$ board, these values were $0.71 \mathrm{~g} / \mathrm{cm}^{3}$ and $4.0 \%$, respectively. Bending strength properties, IB strength and TS value corresponded to a density of $0.65 \mathrm{~g} / \mathrm{cm}^{3}$ calculated based on the regression-line equation from the relationship between each performance value obtained by evaluation tests and density of the specimen.

In addition, for the sake of comparison of the physical and mechanical properties of the manufactured strand board in this study, we added the standard values of type 18 PB, type 24-10 PB of JIS A 5908, commercial OSB and commercial plywood for structure to the following figures. Moreover, strand board with target density of $0.65 \mathrm{~g} / \mathrm{cm}^{3}$ bonded with isocyanate compound adhesive with resin content of $6 \%$ was manufactured as control board. Strand length and orientation of the control board was similar with those of strand board bonded with disposal EPS manufactured in this study. The properties of both boards were also compared.

\section{Bending strength properties}

Figure 2 shows modulus of rupture (MOR) of a parallel specimen of strand board. The MOR of $\mathrm{P}$ board exceeded the standard value of $18 \mathrm{~PB}$ and 24-10 PB. In addition, the MOR of M board was larger than that of control board, commercial OSB and commercial plywood for structure. Figure 3 shows modulus of elasticity (MOE) of a parallel specimen of strand board. The MOE of both $\mathrm{P}$ and $\mathrm{M}$ board was larger than that of type $18 \mathrm{~PB}$ standard, 24-10 PB standard and commercial OSB. However, the MOE of both boards was smaller than that of control board.

In this study, the MOR and MOE of M board were larger than those of $\mathrm{P}$ board. This is because disposal EPS is a non polar material and wood strand is a polar material, which makes them difficult to bond together in $\mathrm{P}$ board. From the results of $\mathrm{M}$ board, isocyanate compound adhesive had been found to be an effective coupling agent to improve bonding strength between the strands. Therefore, bending strength properties of $\mathrm{M}$ board were larger than those of $\mathrm{P}$ board.

\section{Internal bond (IB) strength}

Figure 4 shows IB strength of strand board. IB strength of $\mathrm{P}$ board exceeded the standard value of type $18 \mathrm{~PB}$ and $24-10 \mathrm{~PB}$. From this result, it was clear that strand board bonded with disposal EPS as binder had sufficient strand-to-strand glue joint. Consequently, it was considered that the stress between the strands transferred uniformly and it affected to the improvement of mechanical properties of the board. In addition, IB

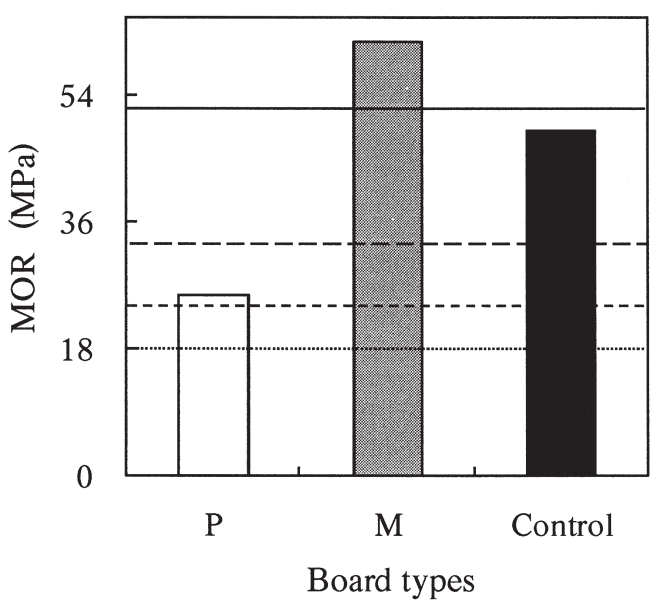

Fig. 2. Modulus of rupture (MOR) of parallel specimen of strand board manufactured in this study.

Legend: dot line, type $18 \mathrm{~PB}$ standard; dash line, type 24-10 PB standard; long dash line, commercial OSB; solid line, commercial plywood for structure.

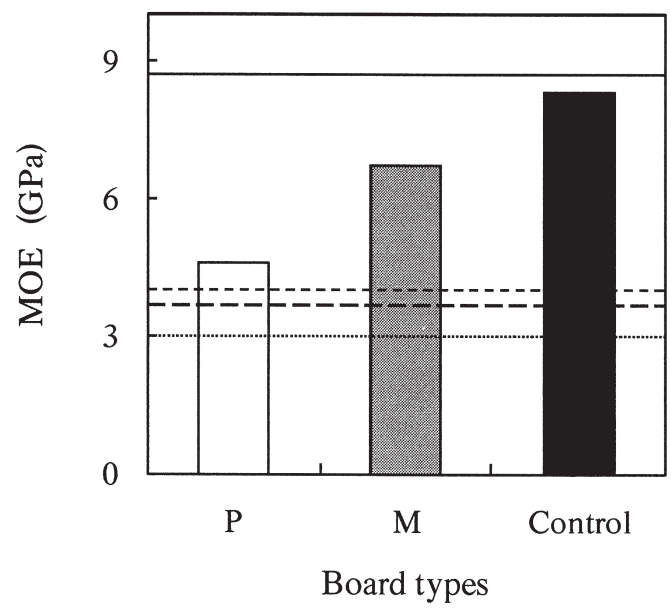

Fig. 3. Modulus of elasticity (MOE) of parallel specimen of strand board manufactured in this study.

Legend: symbols are shown in Fig. 2.

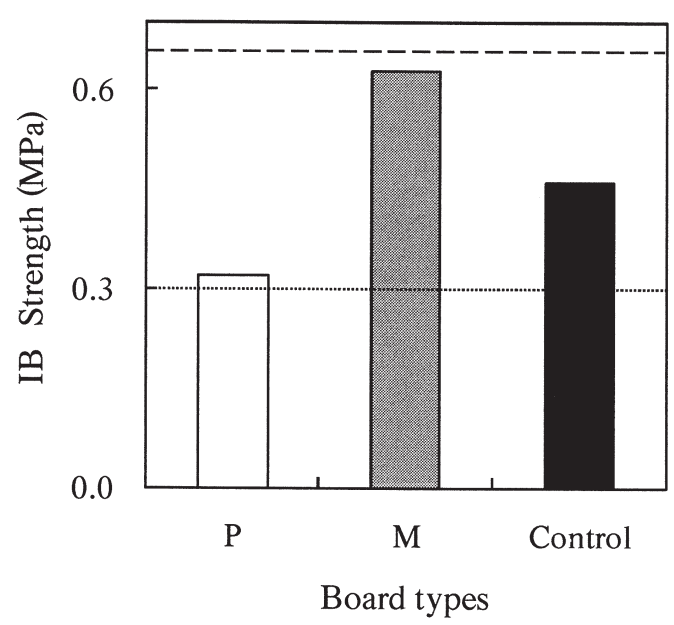

Fig. 4. Internal bond (IB) strength of strand board manufactured in this study.

Legend: dot line, type $18 \mathrm{~PB}$ and 24-10 B standard; long dash line, commercial OSB. 
strength of M board was larger than that of control board. However, IB strength of M board was lower than that of commercial OSB.

\section{Thickness swelling (TS)}

Figure 5 shows TS of strand board manufactured in this study. After $24 \mathrm{~h}$ water immersion, the TS of P board was very large, and the value was larger than that of type 24-10 PB standard. It has been widely known that resin can serve as a swelling-resistant agent. From this result, disposal EPS as binder could not resist the swelling of the board due to breakage of strand-to-strand glue joint. Consequently, gaps and cracks in the surface of the specimen of P board were occurred. Moreover, it is well known that strand board has larger thickness swelling than other wood composites when exposed to high rela-

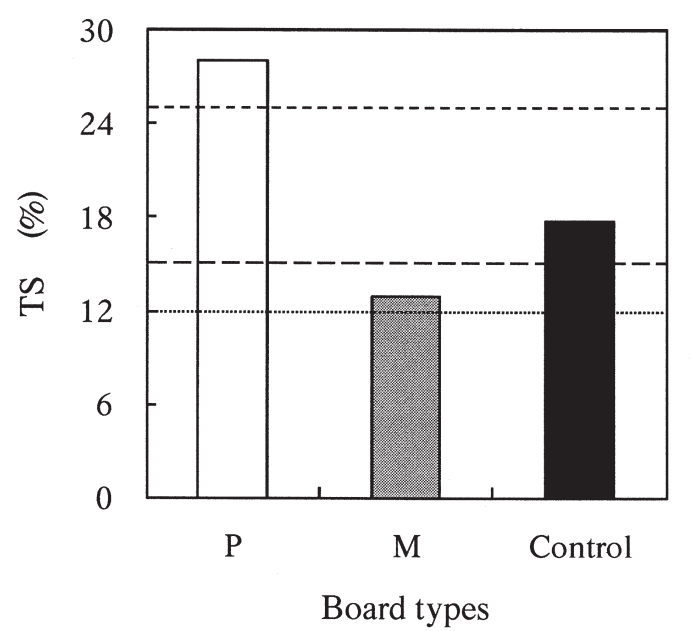

Fig. 5. Thickness swelling (TS) of strand board manufactured in this study.

Legend: symbols are shown in Fig. 2. tive humidity conditions and in the direct contact with water. Therefore, these results remained a problem regarding the water-proof property of the board. On the other hand, the TS of M board was more improved than that of $\mathrm{P}$ board, and the TS was smaller than that of control board and commercial OSB.

\section{CONCLUSIONS}

In this study, strand boards bonded with disposal EPS as binder were manufactured. The physical and mechanical properties of the board were investigated. The main results obtained are as follows:

1. Bending strength properties and IB strength of $\mathrm{P}$ board were larger than those of type $18 \mathrm{~PB}$ and 24-10 PB standard. However, TS of the board was large, and the problem in water-proof property of the board remained.

2. Bending strength properties, IB strength and TS of $\mathrm{M}$ board were larger than those of type 24-10 PB standard, and the performance of M board showed equal or larger than those of control board.

\section{REFERENCES}

Fukuda K, Kashiwai S, Tominaga Y, Ohmi M 2001 Recycling use of Styrofoam waste as glue for bonding wood material. Mokozai Kogyo 56(10): 458-463

Hayashi K, Oh-hori J, Ohmi M, Tominaga H, Fukuda K 2003 Physical properties and incombustibility of particleboard using Styrofoam waste as binder. Mokuzai Kogyo 58(3): 106-111

Hermawan A, Ohuchi T, Fujimoto N 2009 Effects of strand length and orientation on properties of strand board made from construction scrap wood. Journal of the Forest Biomass Utilization Society (accepted)

Japanese Industrial Standard 2006 JIS A 5908: Particleboard 